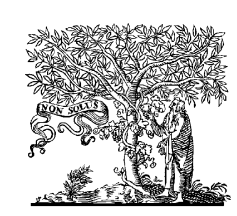

ELSEVIER

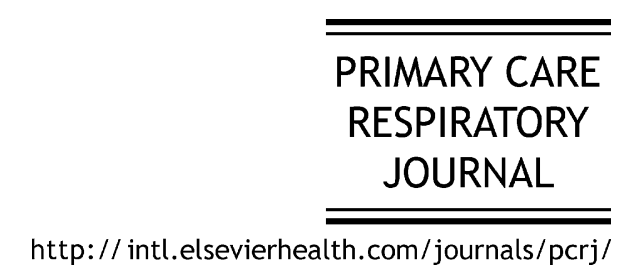

JOURNAL ROUND-UP

\section{Treatment of preschool wheeze with inhaled steroids: new evidence}

Andrew Bush*

Professor of Paediatric Respirology, Imperial College and Royal Brompton Hospital, London, UK

* Tel.: +44 2073518232.

E-mail address: A.Bush@rbht.nhs.uk.

Three important large, randomised, placebocontrolled trials have established clearly what can and cannot be expected of inhaled corticosteroids (ICS) in the under fives.

Guilbert TW, Morgan WJ, Zeiger RS, et al. Long-term inhaled corticosteroids in preschool children at high risk for asthma. N Engl J Mc: 2006;354:1985-1997.

Background: The aim yas to $=\mathrm{C}$ wivether ICS modified the subsecliert development of asthma in preschool chicr =n at high rish torcostil ra

Methods: 285 participants, two or three years of age, with a positive asthma predictive index, were randomly alloted treatment with fluticasone propionate ( $88 \mu \mathrm{g}$ twice daily) or placebo for two years, followed by a one-year period of observation without study medication. The primary outcome was the proportion of episode-free days during the observation year.

Results: During the observation year, there were no differences in the proportion of episodefree days, the number of exacerbations, or lung function. During the treatment period, fluticasone treatment was associated with a greater proportion of episode-free days $(P=0.006)$, a lower exacerbation rate $(P<0.001)$ and less use of controller medication $(P<0.001)$. In the fluticasone group, the mean increase in height was $1.1 \mathrm{~cm}$ less at 24 months $(P<0.001)$, but by the end of the trial the height increase was $0.7 \mathrm{~cm}$ less $(P=0.008)$. Thus, during treatment, fluticasone reduced symptoms and exacerbations to a modest extent, but slowed growth, albeit temporarily and not progressively.

Conclusions: In preschool children at high risk for asthma, two years of ICS therapy did not change the development of asthma symptoms or lung function during a third, treatment-free year. These findings do not provide support for a subsequent disease-modifying effect of ICS after the treatment is discontinued. Although conceivably higher doses may have been disease modifying, significant side effects in this low-dose study are likely to preclude this being investigated.

Bisgaard $H$, Hermansen MN, Lclailic $L$, et al. Intermittent inhaled colticosteroids in infants with ecisolic v/heezing. N Engl J Med 2006:354.1998-2005.

Background: "Thilder who develop persistent whe ar a d acpic asthma often start with a phase cf recurrent episodes of wheezing during the first years of life, usually in association with a viral infection, and with no symptoms between viralinduced episodes. The authors hypothesised that ICS therapy during symptomatic episodes in this early phase might delay progression to persistent wheezing.

Methods: One-month-old infants were randomly assigned to treatment with two-week courses of inhaled budesonide $(400 \mu \mathrm{g}$ per day) or placebo, initiated after a three-day episode of wheezing, in a single-centre, randomized, doubleblind, prospective study lasting three years. The primary outcome was the number of symptom-free days; key secondary outcomes were the time to discontinuation due to persistent wheezing, and safety as evaluated by height and bone mineral density at the end of the study.

Results: 411 infants were randomly assigned: 294 received budesonide. There was no effect of treatment on symptom-free days, nor in the proportion who went on to persistent wheezing. This latter finding was unaffected by the presence 
or absence of atopic dermatitis. There were no safety issues.

Conclusions: Intermittent low dose ICS therapy had no effect on the progression from episodic to persistent wheezing and no short-term benefit during episodes of wheezing in the first three years of life.

Comment: I still feel there is a need for a proper trial of short-term, high dose inhaled steroids at the time of viral wheeze, for example budesonide $1 \mathrm{mg}$ bd for five days; this might improve symptoms, but I doubt would be diseasemodifying.

Murray CS, Woodcock A, Langley SJ, et al. Secondary prevention of asthma by the use of inhaled fluticasone dipropionate in wheezy infants (IWWIN): double-blind, randomised controlled study. Lancet 2006;368:754-762.

Background: The hypothesis was that to prevent loss of lung function and worsening asthma later in childhood, anti-inflammatory treatment needs to be started early in life.

Methods: This was a more complex study design. It was a randomised, double-blind, placebocontrolled study of inhaled fluticasone propionate $100 \mu \mathrm{g}$ twice daily in young children who were followed prospectively, and randomised ciler either one prolonged (greater than olie rnohth) or two medically-confirmed vin=ez, episodes. The

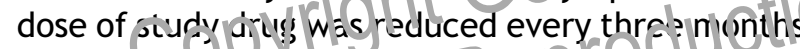
to the mirimum needed. fto s mpicins were not under control by three moriths, open-label fluticasone propionate $100 \mathrm{mcg}$ twice daily was added to the treatment. Children were followedup to five years of age, at which point we gave their parents or guardians questionnaires, and measured the children's lung function and airway reactivity.

Findings: 173 (85 treatment, 88 placebo) of 200 randomised children completed the followup at age five years. There was no treatment effect at age five for the proportion of children with current wheeze, physician-diagnosed asthma, or use of asthma medication, lung function, or airway reactivity. There were no differences in the results after adjustment for open-label fluticasone propionate, nor between the two groups in the time before the open-label drug was added, nor in the proportion needing the open-label drug.

Interpretation: The early use of inhaled fluticasone propionate for wheezing in preschool children had no effect on the natural history of asthma or wheeze later in childhood, and did not prevent lung function decline or reduce airway reactivity.

\section{Commentary on these three papers}

There might be two reasons for prescribing ICS to pre-school children: firstly, prevention of current symptoms; and secondly, interruption of progression to persistent wheeze. Guilbert et al. have shown that, in a high-risk group of children, there may be modest benefits. High risk was defined as: a history of four or more wheezing episodes, at least one of which was physician-diagnosed; plus one major (parental history of asthma, doctordiagnosed atopic dermatitis, sensitization to at least one aeroallergen, or wheezing unrelated to colds) or two minor (allergic sensitization to at least one of egg, milk or peanuts, blood eosinophil count $>4 \%$ ) criteria. Murray et al. showed that if inhaled steroids were given to 'all comers' who had previously wheezed, there was no symptomatic benefit, thereby confirming previous studies that benefits were much less likely in the non-atopic wheezers [1].

The roots of much asthma are in early life, and it is surely at this time that we must intervene to try to prevent a chronic bander of ciisease. How do we do this? In tarris of disease prevention in adults it has bus bown that delayed initiation oil $s$ therapy prejudices long-term lung function; in other vionds Garly use of ICS may indeed be disease rinodifying. The present studies have established unequivocally that this is not the case in preschool children. Neither intermittent (Bisgaard) nor continuous (Guilbert, Murray) inhaled steroids made the slightest difference to progression to persistent wheeze, even though the continuous inhaled steroids were sufficient to cause reduction in height. These results would be predictable from a recent study of the pathology of infant wheeze: in a group of symptomatic infants, median age one year, there was no evidence of eosinophilic inflammation on endobronchial biopsy [2]; and bronchoalveolar lavage studies have also failed to show the eosinophilia so characteristic of steroid responsive asthma [3,4].

How then (if at all) should we use ICS in this age group? It is legitimate to trial them for symptomatic benefit particularly in highly atopic children and particularly if they meet the high risk criteria used by Guilbert et al, but they should be discontinued if there is no immediate benefit because there is no long-term disease modifying effect. Pre-school wheeze is different from adult asthma, and should be treated differently.

An epilogue: there is nothing new under the sun. Similar conclusions were reached 15 years ago $[5,6]$, but have been ignored while inhaled steroids 
have been remorselessly over-prescribed to infants. These new papers should not suffer the same fate.

\section{References}

[1] Pao CS, McKenzie SA. Randomized controlled trial of fluticasone in preschool children with intermittent wheeze. Am J Respir Crit Care Med 2002;166:945-9.

[2] Saglani S, Malmstrom K, Pelkonen AS, et al. Airway remodeling and inflammation in symptomatic infants with reversible airflow obstruction. Am J Respir Crit Care Med 2005;171:722-7.

[3] Marguet C, Jouen-Boedes F, Dean TP, Warner JO. Bronchoalveolar cell profiles in children with asthma, infantile wheeze, chronic cough, or cystic fibrosis. Am J Respir Crit Care Med 1999;159:1533-40.

[4] Le Bourgeois M, Goncalves M, Le Clainche L, et al. Bronchoalveolar cells in children $<3$ years old with severe recurrent wheezing. Chest 2002;122:791-7.

[5] van Essen-Zandvliet EE, Hughes MD, Waalkens $\mathrm{HJ}$, et al. Effects of 22 months of treatment with inhaled corticosteroids and/or beta-2-agonists on lung function, airway responsiveness, and symptoms in asthma. The Dutch Chronic Non-specific Lung Disease Study Group. Am Rev Respir Dis 1992;146:547-54.

[6] Waalkens HJ, van Essen-Zandvliet EE, Hughes MD, et al. Cessation of long-term treatment with inhaled corticosteroid (budesonide in children with asthma results in deterioration. The Dutch CNSLD Study Group. Am Rev Respir 1993;148:1252-7.

Do inha edgreroidsaffect growitio?

Review of "Linear growth in prepubertal asthmatic children treated with montelukast, beclomethasone, or placebo: a 56-week randomized double-blind study." Becker A. et al. for the Montelukast Linear Growth Study Group. Ann Allergy Asthma Immunolo. 2006;96:800-807

Alan Kaplan*

Chair, Family Physician Airways Group of Canada

*Tel.: +1 9058831100.

E-mail address: FOR4KIDS@sympatico.co.

This was a thirty-centre study of 360 boys $(6.4$ to $9.4 \mathrm{yrs}$ ) and girls (6.4 to 8.4yrs) with mild persistent asthma. Inclusion criteria were: Tanner development stage I with heights and weights between the 5th and 95th centiles; bone age (based on x-ray of left hand and wrist) being within two years of chronologic age; mild persistent asthma according to GINA guidelines; and a prebeta agonist FEV1 of at least 75\%. Exclusion criteria were: no current respiratory infection; no other pulmonary disease; no severe chronic sinus disease or nasal polyps; and no use of 21 medications that could affect growth (for example, anticonvulsants) or asthma (for example, nasal steroids). These age groups were chosen since they exhibit lesser variability of growth velocity.

After a placebo run-in period, the 360 children were randomized in equal ratios to doubleblind, double-dummy treatment with placebo, beclomethasone $200 \mathrm{mcg}$ twice-daily, or $5 \mathrm{mg}$ montelukast daily, for 56 weeks. The primary endpoint was linear growth velocity. Measurements were also made of markers of bone turnover including serum osteocalcin (bone formation), and urinary $\mathrm{N}$-telopeptide-creatinine ratio (bone resorption).

The study was designed to estimate the difference in linear growth rates between the montelukast and placebo groups with reasonable precision. Specifically, for 100 patients per treatment group, the half-length of the 95\% $\mathrm{Cl}$ for the difference in linear growth rates between the montelukast and placebo groups was expected to be $0.28 \mathrm{~cm}$ per year based on an SD of $1 \mathrm{~cm}$ per year. The study had $80 \%$ power to detect a difference in grovth of $10.4 \mathrm{~cm}$ per year between the boclonethasone and placebo groups

Gesulv: Linear tlone growth rate was lower with ledto inethasone than placebo or mon elurast. Usteocalcin levels were lower in the beclomethasone group than the others. Betaagonist use and oral steroid rescue were higher in the placebo group than both other groups.

Conclusion: While allowing comparable control, montelukast did not affect linear growth in prepubertal mild persistent asthmatic children over a period of 56 weeks, whereas beclomethasone did. Markers of bone formation were lower in the beclomethasone group.

\section{Commentary}

It is well known that inhaled corticosteroids (ICS) can reduce growth velocity in the first year of treatment [1], and that then there is a catchup phase $[2,3]$. Some clinicians remain concerned that the attained adult height is lower than target height in asthmatics treated with ICS in childhood [4]. Growth is also slowed in children with severe asthma, at least partly due to the effects of chronic disease.

This study tells us that low dose ICS in the first year of treatment does cause some growth delay, and that mild asthma does not seem to 
cause growth delay by itself - though we would have needed a comparable non-asthmatic cohort to make this claim definitively. In addition, montelukast allows reasonable parameters of asthma control with decreased beta-agonist use and exacerbations (oral steroid rescues) comparable with low dose ICS.

Previous studies [5-7] comparing montelukast with ICS have found a greater beneficial effect on FEV1 with ICS, especially if the pre-treatment FEV1 was reduced. We also know that some patients will respond to ICS and not leukotriene receptor antagonists (LTRAs), and vice versa [5].

This study does not provide enough evidence for LTRAs to replace ICS treatment as first-line therapy. However, it does suggest that, contrary to most guidelines internationally, LTRA therapy could be initial monotherapy for mild persistent asthma, especially in those children with well-preserved lung function. In those patients who do respond to LTRAs, ongoing therapy may even have some advantages.

\section{References}

[1] Sharek PJ, Bergma DA. The effect of inhaled steroids on the linear growth of children with asthma, a meta-analysis. Pediatrics 2000;106:E8.

[2] Doull IJM. The effect of asthma and its treatment on growth. Arch Dis Child 2004;89:60-3.

[3] Agertoft L, Pederson S. Effect of Long-term treatment with inhaled budesonide on adult height in children with asthma. NEJM 2000;343:1064-9.

[4] Van Bever HP, et al. Does treatment of asthmatic children with inhaled corticosteroids affect their adult height? Pediatric Pulmonol 1999;27:369-75.

[5] Baumgartner RA, Martinez G, Edelman JM, et al. Distribution of therapeutic response in asthma control between oral montelukast and inhaled beclomethasone. Eur Respir J 2003;21:123-8.

[6] Israel E, ChervinskyPS, Friedman B, et al. Effects of montelukast and beclomethasone on airway function and asthma control. Allergy Clin Immunol 2002;110:847-54.

[7] Malmstrom K, rdriguez-Gomez G, Guerra J, et al. Oral montelukast, inhaled beclomethasone and placebo for choronic asthma: a randomized controlled trial. Ann Intern Med 1999;130:487-9.

doi:10.1016/j.pcrj.2006.10.019

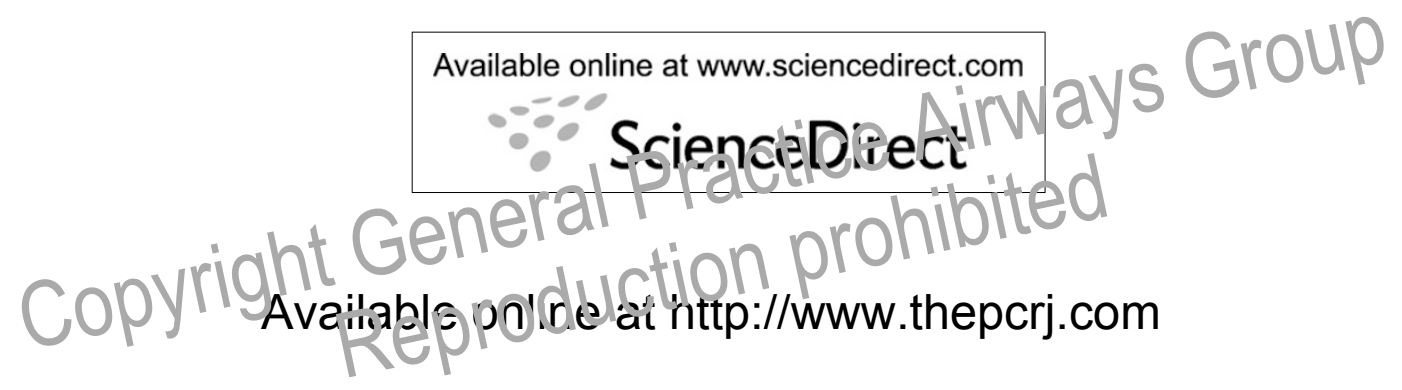

